(D) Check for updates

Cite this: Food Funct., 2020, 11 6680

Received 13th February 2020, Accepted 26th June 2020

DOI: $10.1039 / \mathrm{dOfo00367 \textrm {K }}$

rsc.li/food-function

\section{In vitro study for investigating the impact of decreasing the molecular weight of oat bran dietary fibre components on the behaviour in small and large intestine $\uparrow$}

\author{
Natalia Rosa-Sibakov, (D) *a Noora Mäkelä, ${ }^{\mathrm{b}}$ Anna-Marja Aura, ${ }^{a}$ Tuula Sontag-Strohm ${ }^{\text {b }}$ \\ and Emilia Nordlund ${ }^{a}$
}

\begin{abstract}
The objective of this work was to evaluate the role of $\beta$-glucan molecular weight $\left(M_{w}\right)$ and the presence of other carbohydrates on the physiological functionality of oat bran via an in vitro digestion study. A complete approach using three different in vitro digestion models (viscosity of the small intestine digest, reduction of bile acids and on-line measurement of gas evolution) was used to predict the physiological functionality of enzymatically modified oat bran concentrate (OBC). OBC was enzymatically treated with two $\beta$-glucanase preparations at three different levels in order to specifically decrease $\beta$-glucan $M_{w}$ (Pure: purified $\beta$-glucanase) or $\beta$-glucan and other cell wall polysaccharides (Mix: commercial food-grade cell wall degrading enzyme preparation). The $M_{w}$ of $\beta$-glucan in $O B C$ was tailored to high (1000 kDa), medium $(200-500 \mathrm{kDa})$ and low $(<100 \mathrm{kDa})$ values. The amount of arabinoxylan-oligosaccharides varied from 0.3 to $4.7 \mathrm{~g}$ per $100 \mathrm{~g}$ of $\mathrm{OBC}$ when $\mathrm{OBC}$ was treated with the Mix enzyme at the highest dosage. When the enzymatically treated $O B C s$ were studied in an upper gut model, a decrease in the viscosity of the digest simultaneously with the reduction of $\beta$-glucan $M_{w}$ was observed. At a similar $\beta$-glucan $M_{w}$ range, OBC samples treated with the Pure enzyme had lower viscosity than the samples treated with the Mix one, which also contained arabinoxylan-oligosaccharides. After enzymatic hydrolysis, the capacity of OBC to reduce bile acid was decreased regardless of the enzyme treatment used, and a positive correlation was found between $\beta$-glucan $M_{w}$ and bile acid reduction $(r=0.99 * *)$. The production of colonic gases by the enzymatically treated OBC samples in an in vitro colon model showed an inverse correlation between $\beta$-glucan $M_{w}$ and initial rate of gas formation $(r=-0.9 * *)$, but no impact of arabinoxylan-oligosaccharides was observed. This study emphasised the complexity of factors affecting the functionality of oat components under physiological conditions and demonstrated the possibility to produce $M_{w}$-tailored oat fibre ingredients that could contribute to gut mediated health benefits.
\end{abstract}

\section{Introduction}

Foods rich in oat $\beta$-glucan have four health claims approved by EFSA, i.e. maintenance of normal blood cholesterol levels, reduction of blood cholesterol, limitation of increase in blood glucose levels, and promotion of digestion. ${ }^{1-4}$ The EFSA regulation states that $3 \mathrm{~g}$ of $\beta$-glucan per day should be ingested in order to obtain the claimed cholesterol-lowering effect. The food-authorities specified the amount of $\beta$-glucan, but no

${ }^{a}$ VTT Technical Research Centre of Finland Ltd., P.O Box 1000, FI-02044 VTT, Finland. E-mail: natalia.rosa-sibakov@vtt.fi; Tel: +358406758109

${ }^{b}$ Department of Food and Nutrition, University of Helsinki, P.O. Box 66, FIN-ooo14, Finland

$\dagger$ Electronic supplementary information (ESI) available. See DOI: 10.1039/ dofo00367k further information on the physical form of $\beta$-glucan is specified in the health claim regulation. A recent review on cholesterol-lowering effects suggested that besides the amount of $\beta$-glucan, the molecular weight $\left(M_{\mathrm{w}}\right)$, food matrix (liquid, solid or semi-solid) and level of processing of $\beta$-glucan-rich oatbased foods play important roles. ${ }^{5}$

Several explanations have been pointed out for the mechanisms by which $\beta$-glucan can lower cholesterol and reduce postprandial blood glucose. An increase in the viscosity of intestinal digest, which is affected by the concentration and $M_{\mathrm{w}}$ of $\beta$-glucan, has been presented as the primary factor responsible for the physiological effects of $\beta$-glucan. As $\beta$-glucan is a partially soluble and viscous fibre, its presence in the intestine can delay gastric emptying, delay the digestion of carbohydrates, reduce the absorption of glucose, and suppress the absorption of cholesterol. ${ }^{6,7}$ The interaction of $\beta$-glucan 
with intestinal mucus decreasing its permeability was suggested as one mechanism to reduce the rate of nutrient

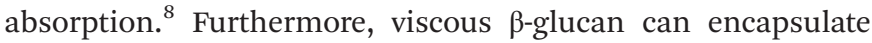
bile acids as they were shown to be associated with $\beta$-glucan aggregates during the gastrointestinal digestion process. ${ }^{9}$ This would prevent the re-absorption of bile acids into the enterohepatic circulation and result in their excretion in the faeces. Consequently, cholesterol is used to produce new bile acids to replace the excreted ones, resulting in decreased level of blood cholesterol, ${ }^{10}$ and lastly, a mechanism related to the fermentability of soluble fibres in the colon has also been suggested. Fermentation of $\beta$-glucan by human intestinal bacteria is related to an increase in short-chain fatty acids, which may also indirectly cause a decrease in blood cholesterol through the inhibition of hepatic cholesterol synthesis. ${ }^{11,12}$

Concerning the physicochemical properties of $\beta$-glucan, the $M_{\mathrm{w}}$ distribution is generally highlighted as one of the main factors that contributes to the physiological effects. Oat $\beta$-glucan with high $M_{\mathrm{w}}$ normally shows viscous flow behaviour, while gelation is observed in samples with low $M_{\mathrm{w}} \cdot{ }^{13}$ A recent meta-analysis showed evidence that consuming oats or oat-containing food products containing at least $3 \mathrm{~g}$ of $\beta$-glucan per day with $M_{\mathrm{W}}>100 \mathrm{kDa}$ reduces serum cholesterol. ${ }^{14}$ However, it seems that the cholesterol-lowering effect strongly depends on both $M_{\mathrm{w}}$ of $\beta$-glucan and the food matrix. For example, in extruded breakfast cereals, low $M_{\mathrm{w}} \beta$-glucan $(210 \mathrm{kDa}) \mathrm{did}$ not have a cholesterol-lowering effect. $^{15}$ In three independent studies with liquid food matrices (e.g. fruit drinks) with low $M_{\mathrm{w}} \beta$-glucan (50-400 kDa), a cholesterol-lowering effect was observed. ${ }^{16-18}$ Concerning the effect of $\beta$-glucan $M_{\mathrm{w}}$ on the glycaemic response, it seems that it also depends on the food matrix and dosage. Tosh et al. ${ }^{19}$ reported a more significant reduction in the glycaemic response with high $M_{\mathrm{w}}(2210 \mathrm{kDa})$ compared to low $M_{\mathrm{w}}(120 \mathrm{kDa})$ when oat $\beta$-glucan was served in muffins. However, Kwong et al. ${ }^{20}$ served oat $\beta$-glucans with 580 or $145 \mathrm{kDa}$ in various concentrations and concluded that the viscosity of the drink itself did not affect its glycaemic response. Recently, Rieder et $a .^{21}$ showed that wheat bread enriched with a high dosage of oat $\beta$-glucan significantly reduced the glycaemic response regardless of $\beta$-glucan $M_{\mathrm{w}}$ and solubility. Thus, the positive health effects of oat-based food should not be defined only by the intrinsic properties of $\beta$-glucan. The interaction of $\beta$-glucan within the food matrix as well as its interaction with other components should also be taken into consideration.

Processing techniques applied for the production of distinct oat-based food rich in $\beta$-glucan are expected to affect also the physicochemical properties, such as solubility and $M_{\mathrm{w}}$ of $\beta$-glucan. The main change occurring to $\beta$-glucan during the processing of oats and oat-based products is depolymerisation, as it has been shown for baking and cooking processes. ${ }^{22,23}$ In liquid and semi-solid oat-based products, $\beta$-glucan depolymerisation is even required. In addition to $\beta$-glucan, modification of other dietary fibre (DF) components of oats is affected by processing. Arabinoxylan (AX), a partially soluble fibre also present in oats and other cereals, undergoes similar depoly- merisation during food processing leading to the formation of arabinoxylan-oligosaccharides (AXOS). Arabinoxylans and AXOS have also several health benefits, including cholesterolreducing effect and glycaemic control, ${ }^{24-26}$ but oat arabinoxylan has been studied less extensively than $\beta$-glucan. Therefore, understanding the synergic effect of DF compounds on the physiological properties of oats would be very important.

The objective of this work is to evaluate the role of $\beta$-glucan $M_{\mathrm{w}}$ and the presence of other carbohydrates (notably AX) on the physiological functionality of oat bran, predicting cholesterol lowering capacity and intestinal comfort. An oat ingredient rich in $\beta$-glucan and arabinoxylan, i.e. oat bran concentrate (OBC), was enzymatically treated with two different DF-degrading enzymes (commercial enzyme mixture and purified $\beta$-glucanase) to prepare OBCs with diverse $M_{\mathrm{w}}$ and the presence or absence of oligosaccharides. An approach of using three different in vitro digestion models was used to investigate potential mechanisms of $\beta$-glucan, i.e. viscosity of the small intestine digest, bile acid retention and gas formation rate, as illustrated in Fig. 1.

\section{Materials and methods}

\subsection{Oat bran concentrate}

Oat bran concentrate (OBC) obtained by a dry milling technique was kindly provided by Fazer Mills (Lahti, Finland). OBC contained $42 \mathrm{~g}$ of total dietary fibre (20.4 insoluble and $21.5 \mathrm{~g}$ soluble), $23.1 \mathrm{~g}$ of starch and $20.1 \mathrm{~g}$ of $\beta$-glucan in $100 \mathrm{~g} \mathrm{~d} . \mathrm{m}$. The total dietary fibre composition of OBC was analysed by AOAC method 991.43. Starch was quantified by using the Megazyme total starch assay kit according to method 76-13.01. The $\beta$-glucan content was determined by a standard method 32-23.01 (AACC, 2000) using the Megazyme $\beta$-glucan mixedlinkage assay kit (Megazyme International Ireland Ltd, Wicklow, Ireland) without ethanol washing.

\subsection{Enzymes and enzymatic hydrolysis conditions}

A commercial cell-wall degrading preparation Depol 740L (Biocatalysts Ltd, Cardiff, United Kingdom) was used to degrade $\beta$-glucan and also other non-starch polysaccharides. This food-grade enzyme preparation had $\beta$-glucanase, xylanase and $\beta$-glucosidase as main activities, ${ }^{27}$ and it is referred in this work as "Mix enzyme". A Trichoderma reesei endoglucanase was produced and purified according to Suurnäkki et al. ${ }^{28}$ The enzyme had $\beta$-glucanase as main activity, and it was devoid of xylanase side-activity. This $\beta$-glucanase preparation is referred to as "Pure enzyme" in this work and it was expected to hydrolyse only $\beta$-glucan, but not other cell-wall polysaccharides. $\beta$-Glucanase activity of Mix and Pure enzymes (9198 and 21980 nkat $\mathrm{mL}^{-1}$, respectively) was assayed as described by Bailey and Nevalainen ${ }^{29}$ but using barley $\beta$-glucan (Megazyme) as the substrate instead of hydroxyethyl cellulose.

The OBC was enzymatically treated with Mix and Pure enzyme at three different dosages: 1,5 and 50 nkat $\mathrm{g}^{-1}$ OBC d. m. The hydrolysis was carried out by mixing OBC, distilled 


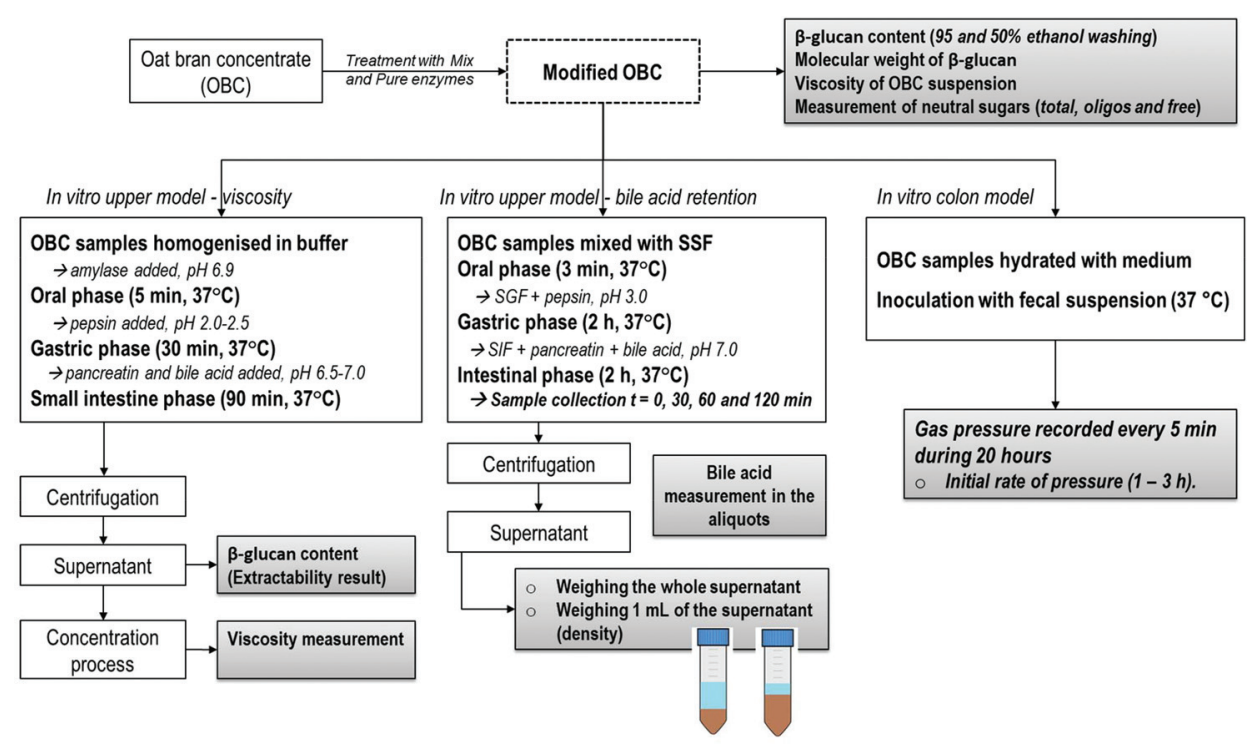

Fig. 1 Set-up of the experimental design.

water and enzymes in order to reach $10 \%$ dry matter content. The incubation was performed with constant mixing (magnetic stirring) for $2 \mathrm{~h}$ at $50{ }^{\circ} \mathrm{C}$ and heating the mixture to $100{ }^{\circ} \mathrm{C}$ (10 $\mathrm{min})$ in the end to terminate the enzyme reaction. A control sample was prepared in the same way without added enzymes. The samples were freeze-dried, ground with a Bamix blender and stored in sealed plastic bags at $16^{\circ} \mathrm{C}$ for further characterization. The treatments were performed in duplicate.

\subsection{Characterization of modified OBC}

2.3.1. $\beta$-Glucan content. The $\beta$-glucan content of the treated OBC samples was determined using the Megazyme $\beta$-glucan mixed-linkage assay kit (Megazyme International Ireland Ltd, Wicklow, Ireland) with different pre-extraction methods. For the measurement of $\beta$-glucan content in OBC samples, a washing with $50 \%$ ethanol was performed according to procedure B in the Megazyme booklet. This washing was performed in order to remove oligosaccharides and free sugars that could have been formed during the enzymatic treatment. Briefly, $200 \mathrm{mg}$ of the sample was mixed with $5.0 \mathrm{~mL}$ of aqueous ethanol $(50 \% \mathrm{v} / \mathrm{v})$, incubated in a boiling water bath for $5 \mathrm{~min}$, and mixed after which further $5.0 \mathrm{~mL}$ of $50 \%(\mathrm{v} / \mathrm{v})$ aqueous ethanol was added. Samples were centrifuged $(1800 \mathrm{~g}, 10 \mathrm{~min})$ and the supernatant removed. The washing was repeated and the remaining pellet was analysed according to the kit instructions.

For the measurement of $\beta$-glucan content of extracts from OBC samples digested in the upper in vitro model, the liquid supernatant was first precipitated with $95 \%$ ethanol and then washed with $66 \%$ ethanol. Briefly, $1 \mathrm{~g}$ of sample was mixed with $3 \mathrm{~mL}$ of $95 \%$ ethanol and centrifuged (10 min, 3220g). Ethanol was discarded and $8 \mathrm{~mL}$ of $66 \%$ ethanol was added, after which the samples were mixed and centrifuged (10 min, $3220 \mathrm{~g}$ ). After ethanol was discarded, the samples underwent $\beta$-glucan content analysis, which was done according to the kit instructions. In order to calculate the extractability of $\mathrm{OBC}$ samples in the upper in vitro model, the $\beta$-glucan contents of OBC samples (not digested) were measured using the same procedure as that used for measuring the $\beta$-glucan contents of the liquid in vitro extracts.

2.3.2. Molecular weight of $\boldsymbol{\beta}$-glucan. OBC samples $(20 \mathrm{mg})$ were dissolved in $10 \mathrm{~mL}$ of $\mathrm{NaOH}(0.1 \mathrm{M})$ and $0.1 \% \mathrm{NaBH}_{4}$ under magnetic stirring at room temperature overnight. The samples were diluted and filtered using a $0.45 \mu \mathrm{m}$ syringe filter. The samples were analysed by high-performance sizeexclusion chromatography (HP-SEC), which consisted of an Alliance 2690 separation module, using Calcofluor white (Fluorescent Brightener 28, Aldrich, Germany) and Scanning Fluorescence 474 detector (Waters Inc., Milford, MA, USA), as described by Suortti. ${ }^{30}$ The linear size-exclusion calibration curve was prepared with $\beta$-glucan standards from Megazyme ranging from 33.6 to $667 \mathrm{kDa}$.

2.3.3. Viscosity of the $\mathrm{OBC}$ suspensions. The viscosity of the enzymatically treated OBCs was measured directly after the treatment (before the enzyme inactivation described above in item 2.2) at $50{ }^{\circ} \mathrm{C}$ with a stress-controlled rotational rheometer (AR-G2; TA Instruments, Crawley, West Sussex, UK) equipped with a cylindrical sample cup $(30 \mathrm{~mm})$ and a four-bladed vane geometry $(28 \mathrm{~mm})$. About $50 \mathrm{~mL}$ of the sample was poured into the measuring cup, the vane was lowered to immerse the blades, and the viscosity was measured with a gradual increase in the shear rate $\left(1-200 \mathrm{~s}^{-1}\right)$. The analyses were performed in triplicate.

2.3.4. Neutral sugars (total, oligosaccharide and free forms). Three different extraction protocols were performed in order to measure total monosaccharides (after acid hydrolysis), oligosaccharides and free monosaccharides. For total monosaccharides, $400 \mathrm{mg}$ of OBCs was hydrolysed with $4 \mathrm{~mL}$ of 
$1.2 \% \mathrm{H}_{2} \mathrm{SO}_{4}\left(60 \mathrm{~min}\right.$ at $\left.120^{\circ} \mathrm{C}\right)$ and centrifuged $(10 \mathrm{~min}$, $1000 \mathrm{~g})$. For the extraction of oligosaccharides with monosaccharides, OBCs (200 mg) were extracted with 50\% ethanol ( $5 \mathrm{~mL}, 5 \mathrm{~min}$ in a boiling water bath), after which more $5 \mathrm{~mL}$ of ethanol was added, mixed and centrifuged (10 min, 1800g). The supernatant was evaporated and replaced by the same weight of Milli-Q water. Acid hydrolysis was performed $(3.5 \mathrm{~mL}$ of sample, $3.5 \mathrm{~mL}$ of Milli-Q water and $0.25 \mathrm{~mL}$ of $70 \% \mathrm{H}_{2} \mathrm{SO}_{4}$ ) during $60 \mathrm{~min}$ at $120^{\circ} \mathrm{C}$. For the extraction of free monosaccharides, OBCs (200 mg) were extracted with 50\% ethanol ( $5 \mathrm{~mL}, 5 \mathrm{~min}$ in a boiling water bath), centrifuged for $10 \mathrm{~min}$ $(1800 \mathrm{~g})$, after which the supernatant was evaporated and the volume adjusted with water. All the samples were filtered prior to injection in HPAEC with pulsed amperometric detection (Dionex ICS-5000 equipped with CarboPac PA20 column). ${ }^{31}$ The amount of oligosaccharides was calculated from the difference between the two latter extractions. All the analyses were carried out in triplicate.

\subsection{In vitro upper model - viscosity}

For the evaluation of the state of $\beta$-glucan in the small intestine (i.e., extractability and viscosity), an in vitro method involving oral, gastric and small intestine was performed according to a method by Mäkelä et al., ${ }^{32}$ where more details can be found. The OBC samples were prepared by weighing $0.8 \mathrm{~g}$ of the freeze-dried sample material and adding $20 \mathrm{~mL}$ of preheated $\left(37^{\circ} \mathrm{C}\right)$ extraction buffer $\left(20 \mathrm{mM} \mathrm{Na}{ }_{2} \mathrm{HPO}_{4}+10 \mathrm{mM}\right.$ $\mathrm{NaCl}, \mathrm{pH}$ 6.9) and $1 \mathrm{~mL}$ of $\alpha$-amylase (Termamyl ${ }^{\circledR} 300 \mathrm{~L}$, Novozymes, Denmark; other enzyme activities inactivated by heat treatment) to each sample. Samples were incubated at $37{ }^{\circ} \mathrm{C}$ for $5 \mathrm{~min}$ with continuous mixing. After this oral phase, the gastric phase was conducted by adjusting the $\mathrm{pH}$ to 2.0-2.5, adding $2 \mathrm{~mL}$ of pepsin solution and incubating at $37{ }^{\circ} \mathrm{C}$ for $30 \mathrm{~min}$ with continuous mixing. In the small intestine phase, the $\mathrm{pH}$ was increased to $6.5-7.0$ and $2 \mathrm{~mL}$ of pancreatin and $1 \mathrm{~mL}$ of bile acid solution were added, prior to incubating at $37^{\circ} \mathrm{C}$ for $90 \mathrm{~min}$ with continuous mixing. Bile acid solution was prepared by mixing $150 \mathrm{mg}$ of bile acids (Bile from bovine and ovine, Sigma, USA) per $\mathrm{mL}$ of $150 \mathrm{mM}$ $\mathrm{NaHCO}_{3}$ at $37{ }^{\circ} \mathrm{C}$ for $30 \mathrm{~min}$. The in vitro extracts were centrifuged $(12900 \mathrm{~g}, 10 \mathrm{~min})$ and the supernatants were collected for further analyses.

From each supernatant, a sample was taken for both viscosity and $\beta$-glucan measurements. In addition, a part of the supernatant was concentrated using a vacuum concentrator (SpeedVac Plus, SC110A combined with Refrigerated Condensation Trap RT100, Savant, Savant Instruments Inc. USA) and samples were taken after $1 \mathrm{~h}$ and $2 \mathrm{~h}$. This concentration step was mimicking the water absorption through the gut membrane in the small intestine, which results in an increased concentration of the compounds in digesta. The $\beta$-glucan content of the supernatants was analysed using a $\beta$-glucan mixed-linkage assay kit (Megazyme International Ireland Ltd, Wicklow, Ireland) according to chapter 2.3.1. The $\beta$-glucan contents of the concentrated samples were calculated based on the weight loss during the concentration step.
Viscosities were measured with a HAAKE MARS 40 rheometer (Thermo Scientific, Germany) using a cone-and-plate measuring geometry with a diameter of $35 \mathrm{~mm}$ and cone angle of $2^{\circ}$. A rotational measurement at $20^{\circ} \mathrm{C}$ was conducted by increasing the shear rate stepwise from $0 \mathrm{~s}^{-1}$ to $300 \mathrm{~s}^{-1}$ after which it was decreased back to $0 \mathrm{~s}^{-1}$. The results are presented as apparent viscosities at a shear rate of $25 \mathrm{~s}^{-1}$ as a function of $\beta$-glucan content.

\subsection{In vitro upper model - bile acid retention}

For the in vitro bile acid retention analysis, the upper intestinal model was performed as described by Minekus et $a l^{33}$ with the following modification: $75 \mathrm{mg} \mathrm{mL} \mathrm{m}^{-1}$ porcine bile extract (B-8631; Sigma) was added in the duodenal phase. This concentration of bile acids ( $6 \mathrm{mM}$ ) was adjusted to be within the physiological range $(1.5-7 \mathrm{mM}){ }^{34}$ Sampling and measurements in the duodenal phase were performed as follows: two $0.5 \mathrm{~mL}$ aliquots were drawn from the duodenal phase $0,30,60$ and $120 \mathrm{~min}$ after starting the incubation. In the end of the duodenal phase $(120 \mathrm{~min})$, samples were centrifuged (5000 rpm, $15 \mathrm{~min},+4{ }^{\circ} \mathrm{C}$ ) and the whole supernatant was weighed. The density $\left(\mathrm{g} \mathrm{mL} \mathrm{mL}^{-1}\right)$ of the supernatant was measured by weighing the mass of $1 \mathrm{~mL}$ of free intestinal fluid (by using the reverse pipetting technique) for the calculation of the volume. The volume of the supernatant was calculated as mass divided by density. Bile concentration in the supernatant (mM) was determined using a kit of Total Bile Acid Assay (DZ042A; Diazyme Laboratories, Poway, California, USA). Before analysis, the samples were diluted $(1: 50)$ in $0.9 \% \mathrm{NaCl}$ according to the kit instructions. The total amount of bile acids, which would be available in the supernatant, was calculated as:

Total free bile acids $(\mu \mathrm{mol})=$ Bile acid concentration $(\mathrm{mM})$ $\times$ Volume $(\mathrm{mL})$

Finally, the reduction of bile acids ( $\mu \mathrm{mol}$ ) was calculated by the difference between the free bile acid in the enzyme blank (i.e., digestive enzymes without any sample) and the free bile acid of the OBC samples, as follows:

$$
\begin{gathered}
\text { Reduction of bile acid amount }(\mu \mathrm{mol}) \\
=\text { Free bile acids } \\
\text { Enzyme control }(\mu \mathrm{mol}) \\
- \text { Free bile acids } \text { OBC }_{\text {OBC }}(\mu \mathrm{mol})
\end{gathered}
$$

This procedure was performed in order to evaluate the bile acid retention of OBC treated samples by taking into account both retention of bile acid into an expanding matrix and direct interaction mechanisms. The in vitro upper model digestion was performed in triplicate for each OBC treatment as well as the bile acid measurement.

\subsection{In vitro colon model for analysis of gas production during fermentation}

The simulated production of colonic gases by OBC treated samples was evaluated by the gas pressure (bar) measured in an in vitro colon model as described by Nordlund et al. ${ }^{35} \mathrm{~A}$ 
fructo-oligosaccharide (FOS) (Orafti®P95, Beneo; DP 2-8) was analysed as a separate control that is known to be fast fermented in the colon model. The device recorded the gas pressure (bar) by 5 min intervals during 20 hours when the evolution reached a constant plateau. The measurement was performed with at least four replicates to ensure good reproducibility. The initial rate of pressure produced by the samples during the in vitro colonic fermentation was calculated between 1 and 3 hours (bar per h). This period was chosen due to the different angular coefficients demonstrated by the samples during the evolution, which could predict some intestinal discomfort. The statistical analysis for the averages of initial rate of pressure was based on one-way ANOVA followed by a TukeyKramer HSD post-hoc test at the 95\% confidence level $(p<$ $0.05)$.

\section{Results and discussion}

\subsection{Impact of enzymatic hydrolysis on the molecular weight} of oat bran polymers

The OBC control presented high $M_{\mathrm{w}}(\sim 1000 \mathrm{kDa})$ and a single peak in the $M_{\mathrm{w}}$ distribution curve (Fig. 2) as is typical of oat $\beta$-glucan. ${ }^{36}$ The depolymerisation of $\beta$-glucan was observed after enzymatic treatment using both enzymes (Mix and Pure) (Fig. 2). The $M_{\mathrm{w}}$ distribution of samples treated with Mix enzyme presented one main peak (Fig. 2A), even though the dispersity was higher than that of the OBC control (Table 1). The $M_{\mathrm{w}}$ of OBC was decreased to 483,232 and $104 \mathrm{kDa}$ with
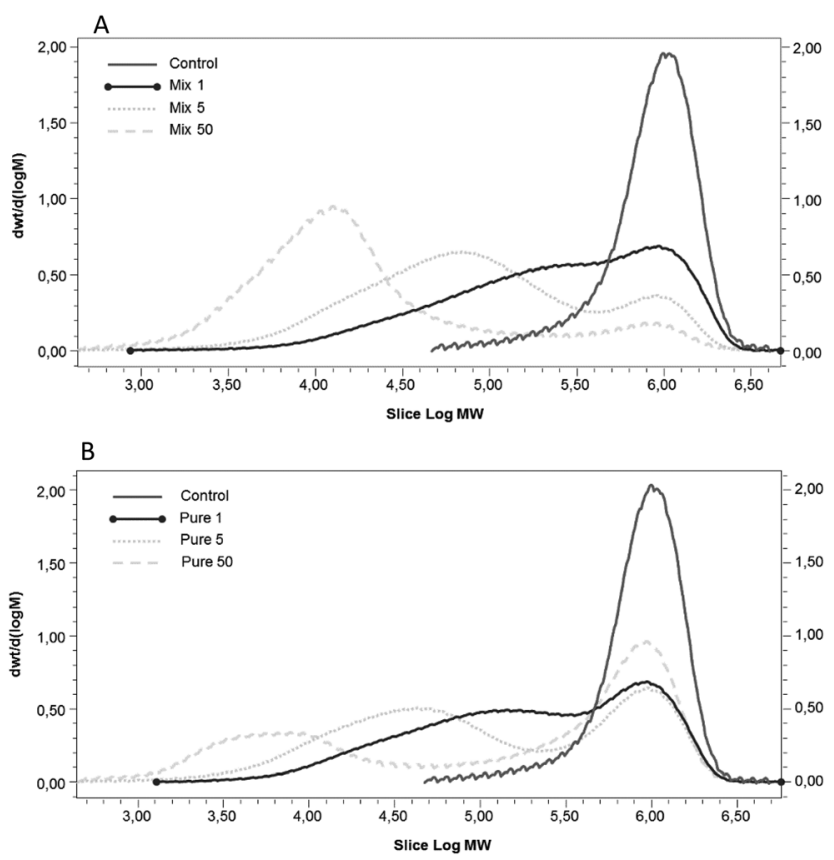

Fig. 2 Molecular weight distribution of $\beta$-glucan in OBC enzymatically treated with (A) Mix and (B) Pure enzymes $\left(1,5\right.$ or 50 nkat $\mathrm{g}^{-1}$ ). Control refers to the $O B C$ treated under the same conditions but without any enzyme.
Mix enzyme at the dosages of 1, 5 and 50 nkat $\mathrm{g}^{-1}$, respectively. The lowest $M_{\mathrm{w}}$ value reached $(100 \mathrm{kDa})$ when treated with 50 nkat $\mathrm{g}^{-1}$ is in agreement with some previous work. ${ }^{36,37}$ Pure enzyme also decreased the $M_{\mathrm{w}}$, but these samples were more heterogeneous, having two peaks and higher values of dispersity (Fig. 2B), suggesting that a portion of the $\beta$-glucan was inaccessible to the enzyme activity. At the lowest dosage (1 nkat $\mathrm{g}^{-1}$ ), Pure and Mix enzyme produced samples with similar $M_{\mathrm{w}}$ (455 and $483 \mathrm{kDa}$, respectively) and $M_{\mathrm{w}}$ distribution. However, when the dosage was increased to 5 and 50 nkat $\mathrm{g}^{-1}$, Pure enzyme could not hydrolyse $\beta$-glucan as efficiently as Mix enzyme. This result is presumably due the sideactivities of Mix enzyme, which can degrade other cell-wall polysaccharides, such as $\mathrm{AX}^{38}$ The degradation of the cell walls structures by Mix enzyme probably led the OBC to be more susceptible to $\beta$-glucanase action.

The extent of $\mathrm{AX}$ degradation in OBC samples was measured by the amount of arabinose and xylose in free and oligosaccharide forms. The amount of free xylose and arabinose was close to zero in all samples (Table 1). Only the Mix enzyme treatment with the highest dosage showed increased free arabinose and xylose content. The amount of arabinoxylan-oligosaccharide in the OBC control sample (no enzyme treatment) was $0.3 \mathrm{~g}$ per $100 \mathrm{~g}$ and this amount increased up to $4.7 \mathrm{~g}$ per $100 \mathrm{~g}$ in the highest dose of Mix enzyme (50 nkat $\mathrm{g}^{-1}$ ) in a dose-dependent manner (Table 1). The arabinoxylanoligosaccharide in OBC treated with Mix samples had a lower arabinose to xylose ratio (0.5-0.7) than the OBC control (1.8). The commercial preparation used as a Mix enzyme in this work has been previously reported to efficiently solubilize AX in oat bran. ${ }^{37}$ OBC treated with Pure enzyme had a similar amount of arabinoxylan-oligosaccharide as in the control sample regardless of the enzymatic dosage (Table 1). This Pure enzyme was also previously reported not to have xylanase activity; the enzyme did not release xylose when kraft pulp was used as the substrate. ${ }^{28}$ The arabinoxylan-oligosaccharide in OBC treated with Mix samples had a similar arabinose to xylose ratio (1.5-1.9) to that of the OBC control (1.8).

The $\beta$-glucan content in OBC samples measured without ethanol washing was similar for all the samples and for the OBC raw material (around $19.8 \mathrm{~g}$ per $100 \mathrm{~g}$ ). The $\beta$-glucan content in OBC samples was measured after ethanol washing at two different concentrations (95 and 50\%). Ethanol washing is generally applied to remove the free sugars from the sample. The higher the ethanol concentration, the washing step retains more low molecular weight polymers (oligosaccharides) for $\beta$-glucan analysis. The $\beta$-glucan content of the OBC samples measured after the $95 \%$ ethanol washing was in the same range as that of the raw material OBC, which was measured without ethanol washing (19.8 g per $100 \mathrm{~g}$ ) (Table 1). The exception was the OBC treated with 50 nkat $\mathrm{g}^{-1}$ of Mix and Pure enzymes, which had a lower amount of $\beta$-glucan (16.4 and $16.9 \%$, respectively) when the $95 \%$ ethanol washing was applied. When the ethanol washing was performed at 50\% concentration, the amounts of $\beta$-glucan in OBC treated with 50 nkat $\mathrm{g}^{-1}$ of both Mix and Pure enzymes had a much lower 
Table 1 Characterization of OBC enzymatically treated with glucanases

\begin{tabular}{|c|c|c|c|c|c|c|c|c|c|c|c|c|c|c|c|c|}
\hline & \multicolumn{4}{|c|}{$\beta$-Glucan } & \multicolumn{4}{|c|}{$\begin{array}{l}\text { Total sugars } \\
(\mathrm{g} \text { per } 100 \mathrm{~g} \text { dm })\end{array}$} & \multicolumn{4}{|c|}{$\begin{array}{l}\text { Oligosaccharide } \\
\text { sugars }(\mathrm{g} \text { per } \\
100 \mathrm{~g} \mathrm{dm})\end{array}$} & \multicolumn{4}{|c|}{$\begin{array}{l}\text { Free sugars } \\
(\mathrm{g} \text { per } 100 \mathrm{~g} \text { dm) }\end{array}$} \\
\hline Control & 948 & 1.5 & $19.8 \pm 0.4$ & $17.0 \pm 0.1$ & 60.9 & 5.5 & 8.4 & 12.2 & 1.2 & 0.2 & 0.1 & 0.3 & 0.0 & 0.0 & 0.0 & 0.0 \\
\hline Mix 1 & 483 & 6.1 & $18.3 \pm 0.5$ & $19.8 \pm 1.0$ & 58.9 & 5.1 & 7.8 & 11.4 & 1.1 & 0.4 & 0.6 & 0.9 & 0.0 & 0.0 & 0.0 & 0.0 \\
\hline Pure 1 & 455 & 7.3 & $19.5 \pm 0.4$ & $20.4 \pm 0.4$ & 59.8 & 5.3 & 8.1 & 11.8 & 1.8 & 0.3 & 0.1 & 0.4 & 0.0 & 0.0 & 0.0 & 0.0 \\
\hline Pure 5 & 390 & 14.5 & $19.4 \pm 0.2$ & $16.8 \pm 1.0$ & 58.5 & 5.3 & 8.0 & 11.7 & 4.4 & 0.3 & 0.2 & 0.4 & 0.0 & 0.0 & 0.0 & 0.0 \\
\hline Pure 50 & 378 & 30.1 & $16.9 \pm 0.1$ & $4.0 \pm 0.6$ & 56.1 & 5.0 & 7.6 & 11.1 & 12.7 & 0.3 & 0.2 & 0.5 & 0.0 & 0.0 & 0.0 & 0.0 \\
\hline
\end{tabular}

$M_{\mathrm{w}}=$ weight average molecular weight, $D=$ dispersity $\left(M_{\mathrm{w}} / M_{\mathrm{n}}\right)$, Glu $=$ glucose, Ara $=$ arabinose, Xyl $=$ xylose, $\mathrm{AX}=\mathrm{Arabinoxylan}=0.88 \times(\mathrm{Ara}+\mathrm{Xyl})$. The relative standard deviation of sugar analysis was smaller than $10 \%$ and is not presented in the Table.

amount of $\beta$-glucan (1.6 and $4.0 \mathrm{~g}$ per $100 \mathrm{~g}$, respectively). The results indicate that a significant amount of depolymerized $\beta$-glucan was washed out in the measurement after $50 \% \mathrm{EtOH}$ precipitation. When the amount of glucose in oligosaccharide form was measured from the $50 \%$ ethanol solutions used for washing the same OBC samples, OBC treated with Mix 50 nkat $\mathrm{g}^{-1}$ and Pure 50 nkat $^{-1}$ contained 13.6 and $12.7 \mathrm{~g}$ per $100 \mathrm{~g}$ glucose, respectively. Furthermore, the free glucose content of the corresponding samples was negligible. These results propose that the enzymatic treatment led to the formation of $\beta$-gluco-oligosaccharides, but it was not harsh enough to significantly degrade $\beta$-glucan into free glucose. It is important to note that when analysing the $\beta$-glucan content and quality of processed oat samples, applying the correct ethanol concentration is critical to enable correct interpretation of the results.

The viscosity of the OBC control sample in suspension was the highest (Fig. 3A), which is expected and in agreement with the high $M_{\mathrm{w}}(\sim 1000 \mathrm{kDa})$ of this sample. ${ }^{13}$ The enzymatic treatment reduced the viscosity of all the samples and this reduction was concomitant with the enzymatic dosage. At 1 and 5 nkat $\mathrm{g}^{-1}$, OBCs treated with Mix enzyme had higher viscosity than the corresponding OBC sample treated with Pure.
Since Mix enzyme 1 nkat $\mathrm{g}^{-1}$ and Pure enzyme 1 nkat $\mathrm{g}^{-1}$ had very similar $\beta$-glucan $M_{\mathrm{w}}$, and Mix enzyme 5 nkat $\mathrm{g}^{-1}$ had lower $\beta$-glucan $M_{\mathrm{w}}$ than Pure enzyme 5 nkat g $^{-1}$, the higher viscosity values of Mix enzyme samples suggest that solubilisation, but not significant depolymerization of $\mathrm{AX}$ at 1 and 5 nkat $\mathrm{g}^{-1}$ might have contributed to the higher viscosity of these OBC samples. However, at $50 \mathrm{nkat}^{-1}$, no difference in the viscosity was observed, most probably due to the intensive depolymerisation of both $\beta$-glucan and arabinoxylan (Fig. 3A).

\subsection{Extractability of $\beta$-glucan and viscosity of the small intestine digest from OBCs}

The in vitro extractability (Table 2) was studied by analysing the $\beta$-glucan content of the in vitro extract. This extractability describes the relative amount of $\beta$-glucan that has the potential to be physiologically functional and it is a requirement for the intestinal viscosity. The in vitro extractability of the $\mathrm{OBC}$ control was $42.4 \%$ and this value was significantly increased for all the enzymatically treated OBCs (Table 2). The Mix 5 OBC had the highest extractability (86.7\%). Comparing the samples treated with Mix and Pure enzymes, the extractability of Mix ones was higher than that of Pure at similar dosages.
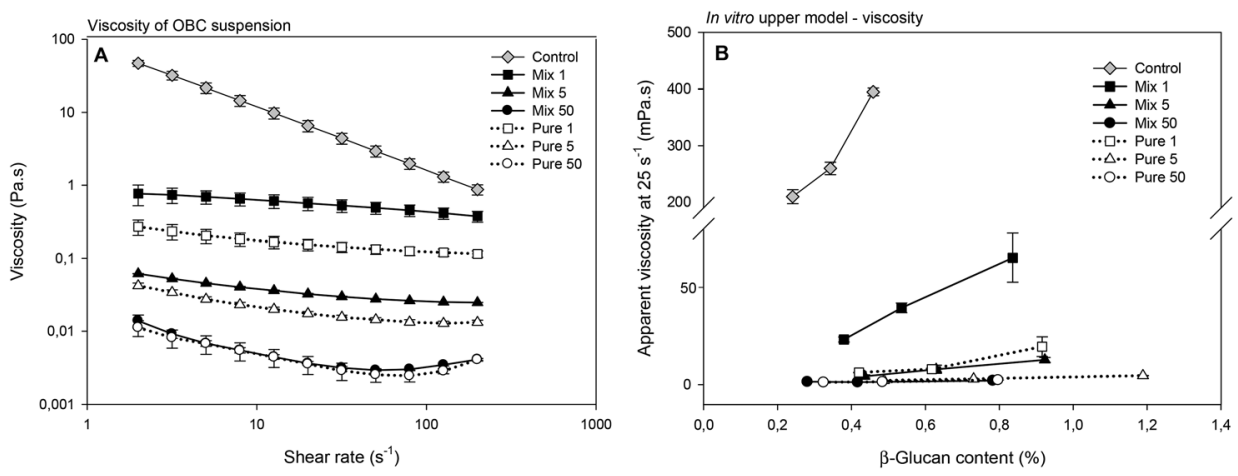

Fig. 3 (A) Viscosity (Pa s) as a function of the shear rate $\left(\mathrm{s}^{-1}\right)$ of $\mathrm{OBC}$ enzymatically treated with Mix or Pure enzymes (1, 5 or 50 nkat $\left.\mathrm{g}^{-1}\right)$. (B) Apparent viscosity ( $\mathrm{mPa} \mathrm{s}$, measured at $25 \mathrm{~s}^{-1}$ ) of the in vitro extracts digested in the upper gut model as a function of the $\beta$-glucan content (\%) of OBC enzymatically treated with Mix or Pure enzymes $\left(1,5\right.$ or 50 nkat $\left.\mathrm{g}^{-1}\right)$. Control refers to the OBC treated under the same conditions but without any enzyme. 
Table 2 In vitro characterization of OBC enzymatically treated with glucanases: $\beta$-glucan extractability (\%) during upper model - viscosity, parameters accessed to measure the reduction of free bile acid $(\mu \mathrm{mol})$ during upper model - bile acid retention, and initial rate of pressure (1 to $3 \mathrm{~h}$ ) (bar per $\mathrm{h}$ ) produced by the samples during the in vitro colonic fermentation

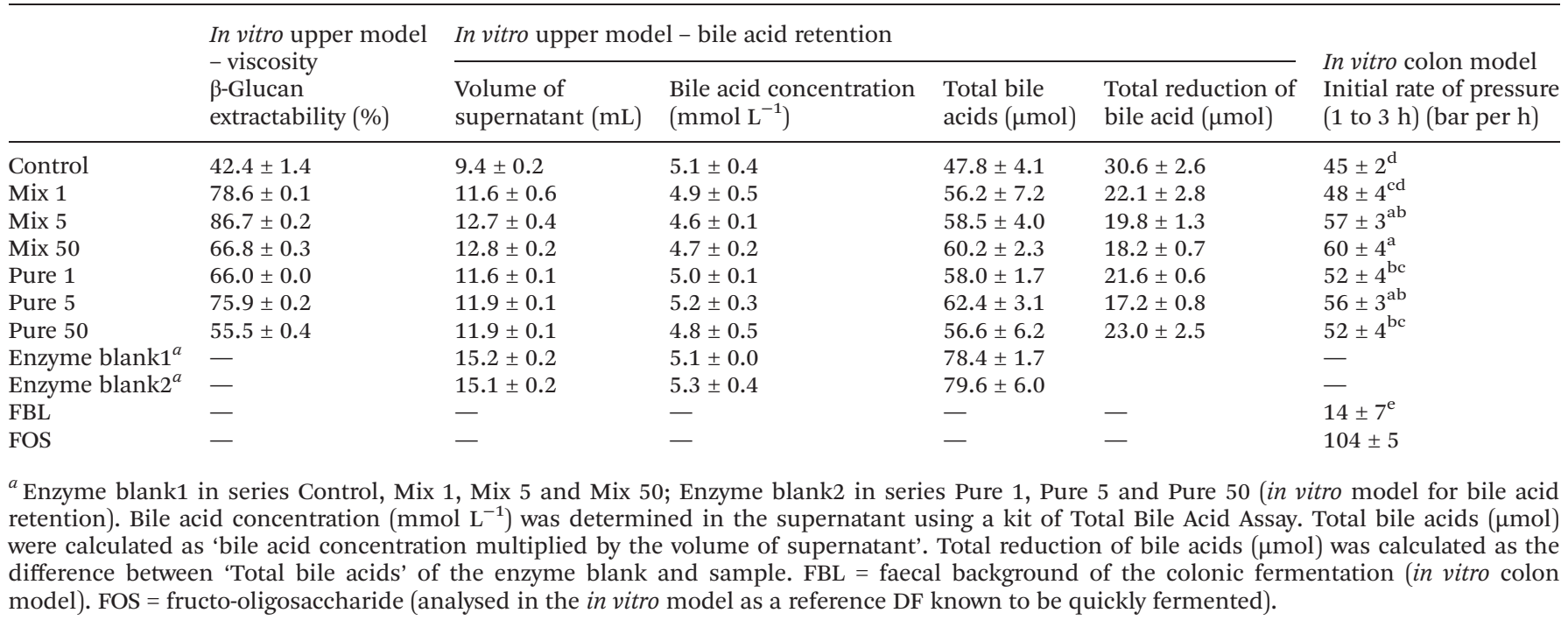

This result is probably due to the hydrolysis of other compounds in the oat matrix that normally entrap $\beta$-glucan and thus hinder its extraction. This goes in line with the effect observed in the $\beta$-glucan $M_{\mathrm{w}}$ reduction during the enzymatic treatment with these two enzymes, where it was discussed that the hydrolysis of cell-wall polysaccharides by Mix enzyme allowed a better and more homogeneous hydrolysis of $\beta$-glucan. With the highest dosage of enzyme $\left(50\right.$ nkat $\left.^{-1}\right)$, the extractability appeared lower than in samples treated with 1 or 5 nkat $\mathrm{g}^{-1}$ (Table 2). This lower extractability was probably caused by the formation of the small $\beta$-gluco-oligosaccharides and free glucose that were washed out in ethanol during the $\beta$-glucan measurement.

The viscosities of the extracts after in vitro digestion were measured and presented as a function of $\beta$-glucan concentration (Fig. 3B). The OBC control had the highest viscosity and the viscosity increased exponentially with increasing $\beta$-glucan concentration. Most of the enzyme hydrolysed OBC samples had negligible viscosity at all tested concentrations, the only exception being the sample hydrolysed with the lowest Mix dosage (1 nkat $\left.\mathrm{g}^{-1}\right)$ (Fig. 3B). Still the viscosity of Mix 1 was significantly lower than the viscosity of the OBC control (e.g. $23 \mathrm{mPa}$ s at a $\beta$-glucan concentration of $0.42 \%$ and $395 \mathrm{mPa} s$ at a $\beta$-glucan concentration of $0.45 \%$, respectively). OBC control had the highest $\beta$-glucan $M_{\mathrm{W}}(\sim 1000 \mathrm{kDa})$, which was the mainly responsible for the highest viscosity observed after in vitro digestion. These results confirm that the high viscosity of the ingredient per se (Fig. 3A) remained even after in vitro digestion. The reduction of $\beta$-glucan $M_{\mathrm{w}}$ by Mix and Pure enzymes $(<500 \mathrm{kDa})$ resulted in much lower viscosity after in vitro digestion. However, it seems that the treatment with Mix enzyme at the lowest dosage $\left(1\right.$ nkat g $\left.^{-1}\right)$ can still keep an intestinal viscosity to some extent. The production of arabinoxylan-oligosaccharides might have contributed to the intestinal viscosity, as the corresponding sample without arabinoxylanoligosaccharides (Pure 1 nkat $\mathrm{g}^{-1}$ ) and similar $\beta$-glucan $M_{\mathrm{w}}$ presented lower viscosity. Indeed, the amount of water-extractable AX has been previously reported to correlate with the viscosity of cereal extracts. ${ }^{39,40}$

\subsection{Impact of enzymatic hydrolysis on bile acid reduction by OBC samples}

Firstly, the concentration of bile acids was measured in the supernatant of aliquots taken during the duodenal stage at time-points 0, 30, 60 and $120 \mathrm{~min}$. The variations of the bile acid concentrations in the presence of OBC treated with Mix enzyme are illustrated in Fig. 4A. The equations of the regression lines indicated a slightly declining trend only for OBC control and Mix 1. The bile acid concentration stayed at a constant level $(4.5-5.3 \mathrm{mM})$ for all samples. These results suggests that a minor direct interaction between the $\mathrm{OBC}$ samples and bile acid has occurred, especially as all the samples reached a similar level of bile acid in the enzyme blank at the end of the incubation time (120 min). Similar results for OBC treated with Pure enzyme were observed (Fig S1, ESI $\dagger$ ).

Secondly, at the end of the duodenal stage $(120 \mathrm{~min})$, the weights, densities and volumes of the whole supernatant were measured. All data and further information on the calculations can be found in the ESI (Table S1 $\dagger$ ). The volume of the supernatant for OBC samples was much lower than the one measured for the enzyme blank (15 mL) (Table 2). The highest difference was in the OBC control $(9.4 \mathrm{~mL})$. The total amount of bile acids which would be freely available in the supernatant was calculated based on the bile acid concentration $(t=$ $120 \mathrm{~min}$ ) multiplied by the volume of the supernatant (Table 2). By the difference with the enzyme blank, the 'The total reduction of bile acids' was calculated (Table 2). OBC 

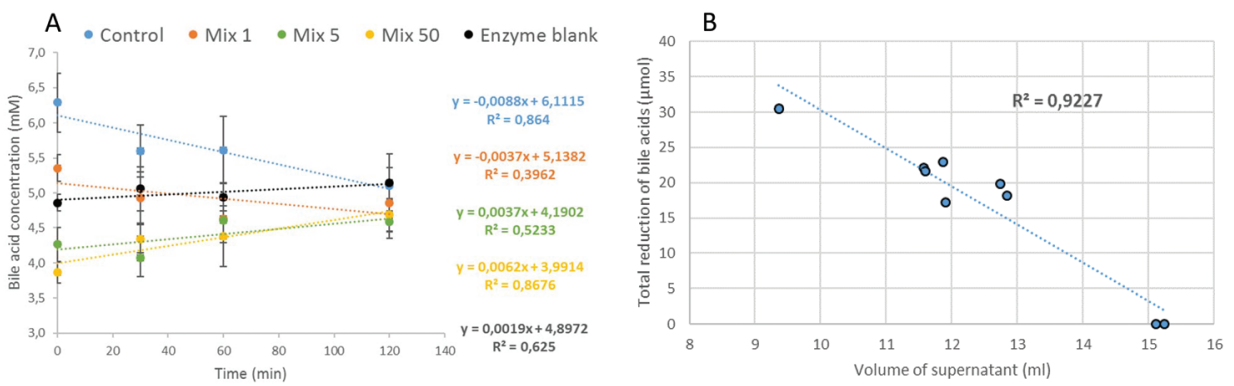

Fig. 4 (A) Changes in bile acid concentration $(\mathrm{mM})$ in duodenal incubation in vitro in the presence of the OBC enzymatically treated with Mix enzyme (1,5 or 50 nkat $\mathrm{g}^{-1}$ ). Equations of the trend lines are expressed as the same colours as the corresponding markers of the curve. (B) Relationship between the volume of supernatant and the total reduction of bile acids measured at the end of in vitro duodenal incubation (120 min) for all OBC samples and enzyme blank. Control refers to the OBC treated under the same conditions but without any enzyme. Enzyme blank means the incubation without any samples, i.e. only digestive enzymes.

control was the most efficient sample to reduce bile acids during in vitro incubation (reduction of $30.6 \mu \mathrm{mol}$ ). The potential of retaining bile acids was decreased when OBC was treated with Mix or Pure enzymes (Table 2). An inverse relation was found between the volume of the supernatant and the capacity of the OBC samples to reduce bile acids (Fig. 4B). This indicates that the OBC samples have swelling properties that encapsulated bile acid in their network. For the OBC treated with Mix enzyme, the potential of reducing bile acids was decreased according to the enzyme dosage used. A positive correlation between $\beta$-glucan $M_{\mathrm{w}}$ and reduction of bile acid ( $r=$ $0.994^{* *}$, Fig S2 in the $\mathrm{ESI} \dagger$ ) was found for OBC treated with Mix enzyme. For the samples treated with Pure enzyme, no significant correlation between $\beta$-glucan $M_{\mathrm{w}}$ and bile acid reduction was found. This lack of correlation could be due to the heterogeneity of OBC treated with Pure enzyme, meaning these samples cannot be characterized by the $M_{\mathrm{w}}$ 'mean' value.

The impact of $\beta$-glucan $M_{\mathrm{w}}$ on bile acid reduction has been previously reported. Hyun and White ${ }^{41}$ showed that waterextracted low $M_{\mathrm{w}} \beta$-glucan (156 kDa) was more effective in binding bile acids than high $M_{\mathrm{w}}$ (687 kDa) (24.3\% vs. $18.9 \%$ of total bile acids). These authors suggested that the impact of the low $M_{\mathrm{w}} \beta$-glucan on the bile acid binding may be related to its being more soluble than high $M_{\mathrm{w}}$. Sayar et al. ${ }^{42}$ also observed a tendency to better bile acid biding in low and medium $M_{\mathrm{w}} \beta$-glucan. The contrary results observed in this work are likely explained by the fact that in the previous studies rather low doses of the $\beta$-glucan ingredient (40-800 mg) were used in the bile acid binding assay, and only changes in bile acid concentrations were considered. However, soluble dietary fibre interact with bile acids either by direct interaction or by entrapment in a viscous or gelatinous network. This means that measuring only the non-bound bile acid in the supernatant does not represent the amount of bile acids that is probably entrapped in the network formed by samples that have a high swelling power as observed in the OBC samples. Indeed, Naumann et al. $^{43}$ suggested that centrifugation methods could underestimate bile acid adsorption in DF-rich materials, as it could not take into account the entrapment of bile acids in the viscous matrix. These authors used a similar digestion model ${ }^{33}$ and reported that different residue volumes were observed depending on the DF material, but only the bile acid concentration in the supernatant was analysed and the authors suggested it as the reason for the underestimated adsorption. In the present work, the reduction of free volume of digest was measured, and thus the mechanism of encapsulation of bile acids by swelling properties and viscosity of ingredients was taken into account. These considerations are important because the ability of $\beta$-glucan to bind bile acid has been previously linked to the high viscosity of $\beta$-glucan in solution rather than direct interaction mechanisms such as complex formation. ${ }^{44}$ By using a dialysis membrane system, Zacherl et al. $^{45}$ observed a correlation between bile acid binding and viscosity of different fibre samples after in vitro digestion. Recently, Marasca et al. ${ }^{46}$ also observed that oat extracts with hydrolysed $\beta$-glucan did not positively affect the bile-acid retention (measured with a dialysis method) and a clear correlation with viscosity was shown. In an in vivo ileostomy study with native and hydrolysed oat brans, it was shown that native oat bran entrapped or encapsulated whole micelles in the small bowel due to its high viscosity. ${ }^{47}$ The hydrolysed oat bran of this latter study probably had an intensively depolymerised $\beta$-glucan as the viscosity reported was very low. Therefore, our results support this hypothesis for $\beta$-glucan ingredients, as the $\mathrm{OBC}$ with the highest $\beta$-glucan $M_{\mathrm{w}}$, estimated by its higher viscosity and swelling power, ${ }^{13,48}$ presented higher bile acid retention than OBC with medium and low $\beta$-glucan $M_{\mathrm{w}}$. Nevertheless, OBCs with medium and low $M_{\mathrm{w}}$ also presented the capacity to reduce bile acids. Therefore, a controlled depolymerisation, which would not extensively hydrolyse $\beta$-glucan, should be intended in order to keep the potential to reduce bile acids.

Comparing OBC treated with Mix vs. Pure enzymes, different results were observed depending on the enzyme dosage used. At 1 nkat g $^{-1}$, the total reduction of free bile acid was similar for Mix and Pure treated OBCs. This result is probably related to the $\beta$-glucan $M_{\mathrm{w}}$ distribution of these samples, because the Mix 1 and Pure 1 had very close curves. At 5 nkat 
$\mathrm{g}^{-1}$, the bile acid retention of OBC treated with Mix was higher than that with Pure enzyme. The contrary was observed at 50 nkat $\mathrm{g}^{-1}$, as Mix 50 seemed to have lower bile acid retention than Pure 50. The presence of arabinoxylan-oligosaccharides in the OBC treated with Mix enzyme did not have an impact on the bile acid reduction (no significant correlation) regardless of the enzyme dosage used. For OBC treated with Pure enzymes, all the samples have a similar amount of arabinoxylan-oligosaccharides and different bile acid reduction capacities, showing again the lack of relationship between bile acid retention and arabinoxylan-oligosaccharides. A soluble wheat arabinoxylan-rich fraction was previously shown to reduce bile acids in a pig model. ${ }^{49}$ However, when AX and $\beta$-glucan are both present in comparable amounts in the sample, it seemed that the impact of $\beta$-glucan on reducing bile acids is much higher than AX or arabinoxylan-oligosaccharides. Bagdi et al. ${ }^{50}$ reported that crosslinked AX presented a higher bile acid capacity than non-treated $\mathrm{AX}$, indicating again that a gel structure formation should happen for bile acid retention.

\subsection{Impact of enzymatic hydrolysis of oat bran on colonic gas formation rate in vitro}

The production of colonic gases during in vitro fermentation, which was recorded by the on-line measurement of gas pressure, was higher in all enzymatically treated OBCs compared to the OBC control (Fig. 5). The final pressure of OBC control was the lowest one $(0.27$ bar $)$ and Pure 5 reached the highest value ( 0.40 bar) at the end of the experiment $(20 \mathrm{~h})$. The initial rates of gas evolution (from 1 to $3 \mathrm{~h}$ ) (Table 2) in OBC control was also the lowest one and Mix 1 was statistically similar to OBC control. The initial rates of Mix 5 and Mix 50 were higher than $\mathrm{OBC}$ and Mix 1, but similar between each other (Table 2). The initial gas formation of the all Pure samples were statistically similar. Inverse correlation between $\beta$-glucan $M_{\mathrm{w}}$ and initial rate of gas formation was observed ( $r=$ $-0.9^{* *}$, Fig S2 in the ESI $\dagger$ ).

This is the first report presenting a correlation between $\beta$-glucan $M_{\mathrm{w}}$ and fermentability in vitro expressed as the initial rate of gas pressure. Kim and White ${ }^{51}$ analysed water-extracted oat fractions (85-92\% $\beta$-glucan) and reported no differences in total gas production for a range of $\beta$-glucan $M_{\mathrm{w}}$. However, the $\beta$-glucan fractions in the $M_{\mathrm{w}}$ range of $87-348 \mathrm{kDa}$ produced greater amounts of SCFA than did those at high $M_{\mathrm{w}}(709 \mathrm{kDa})$ after $24 \mathrm{~h}$ of fermentation. The authors attributed the higher SCFA production to the higher solubility of low $M_{\mathrm{w}} \beta$-glucan. The production/initial rate of SCFA is generally well correlated to the total/initial rate of gas production during the in vitro fermentation model. Therefore, our results are in agreement with Kim and White, ${ }^{51}$ as we observed a lower gas production for the OBC control ( 1000 kDa) compared to enzymatically treated OBCs (483-104 kDa). Mikkelsen et al. ${ }^{52}$ did not observe differences in SCFA production when barley $\beta$-glucan with different $M_{\mathrm{w}}$ (100-530 kDa) was added to the diet of hypercholesterolemic rats. Immerstrand et al. ${ }^{53}$ did not observe a correlation between $\beta$-glucan $M_{\mathrm{w}}(1311,241,56$ or $21 \mathrm{kDa})$ and cholesterol lowering or SCFA production in mice.

The absence of arabinoxylan-oligosaccharides in samples Pure 1, Pure 5 and Pure 50 did not decrease gas formation as compared to the samples with similar $\beta$-glucan $M_{\mathrm{w}}$ containing arabinoxylan-oligosaccharides (Mix 1 and Mix 5). No correlation was found between arabinoxylan-oligosaccharides and initial gas formation. Nevertheless, the gas formation of all oat samples was clearly lower than that with FOS (104 bar per h) which is known to cause intestinal discomfort for some consumers consuming FOS containing foods. With regard to revealing potential intestinal discomfort generated by the increased gas formation by OBC samples, clinical studies are needed. Generally, soluble fibres have higher fermentability compared to insoluble ones. Damen et al. ${ }^{54}$ showed that water-extractable AX from wheat was totally fermented (80-90\%) in the caecumcolon of rats, while water-unextractable AX was only partially (30-40\%) fermented. Therefore, it would be expected in the present study that the OBCs containing higher amounts of arabinoxylan-oligosaccharides would also have higher fermentation rates. One possible explanation is that $\beta$-glucan was more susceptible for fermentation than arabinoxylan-oligosaccharides. The amount of $\beta$-glucan that was depolymerised was higher than the amount of arabinoxylan-oligosaccharides (up to $4.7 \mathrm{~g}$ per $100 \mathrm{~g}$ ), suggesting that the effect of arabinoxylan-
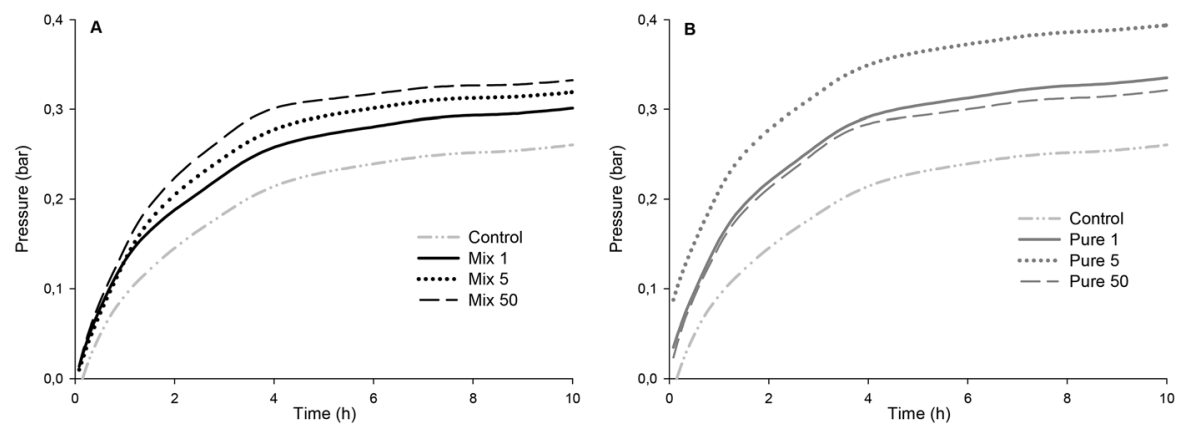

Fig. 5 Time course of gas pressure (measured as maximal pressure, bar) developed by human faecal microbiota during in vitro fermentation $(0-20 \mathrm{~h})$ of $\mathrm{OBC}$ enzymatically treated with (A) Mix and (B) Pure enzymes $\left(1,5\right.$ or 50 nkat $\left.\mathrm{g}^{-1}\right)$. Control refers to the OBC treated under the same conditions but without any enzyme. 
oligosaccharides would not be as strong as that of low $M_{\mathrm{w}}$ $\beta$-glucan. It is also unclear if the AX from oats would have distinct characteristics (e.g. side chain distribution, $\mathrm{A} / \mathrm{X}$ ratio, $M_{\mathrm{w}}$ ) compared to $\mathrm{AX}$ of wheat and rye. However, $\mathrm{AX}$ has been mainly studied for rye and wheat, and no previous reports on fermentability of arabinoxylan-oligosaccharides in oats were found.

\section{Conclusions}

Enzymatic hydrolysis of OBC non-starch carbohydrates or specifically $\beta$-glucan resulted in OBC samples with depolymerized $\beta$-glucan and increased amount of arabinoxylan-oligosaccharides, or OBC samples with $\beta$-glucan of reduced $M_{\mathrm{w}}$. Depolymerisation of the carbohydrates retained most of the DF characteristics and the formation of free sugars was limited. Only with the highest enzyme dosage, $\beta$-glucan and AX content decreased, suggesting too extensive degree of hydrolysis for retaining the initial DF profile. $\beta$-Glucan is proposed to have mostly affected the parameters measured during in vitro digestion, and the arabinoxylan-oligosaccharides were observed to influence mainly the in vitro viscosity, and no difference in gas production and bile-acid retention was detected when compared to modification of $\beta$-glucan $M_{\mathrm{w}}$ only. The OBC treated with Mix enzyme at 1 nkat $\mathrm{g}^{-1}$ (medium $M_{\mathrm{w}}$ : $400-500 \mathrm{kDa}$ ) was detected to be the most potential OBC ingredient which could still have similar benefits to oat $\beta$ glucan samples with higher $M_{\mathrm{w}}(1000 \mathrm{kDa})$, i.e. the intestinal viscosity and the reduction of bile acids were still detectable, and a moderate colonic fermentability, which is not expected to cause intestinal discomfort, was notable. However, this assumption based on the in vitro data should be proven by clinical studies. Generally, the findings of the study encourage the enzyme-aided development of food products rich in oat DF especially in the semi-moist and liquid categories (i.e., spoonables, beverages and yogurts), since the controlled depolymerisation enables better processability, but at the same time retains those features of DF components, which are associated with subsequent intestinal comfort and gut mediated health benefits.

\section{Conflicts of interest}

There are no conflicts to declare.

\section{Acknowledgements}

Funding from Business Finland [5705/31/2016 Oat-derived Wellbeing by Clinical and Perceived Assessment] is gratefully acknowledged. Prof. Kaisa Linderborg (University of Turku) is acknowledged for helpful discussion. Leila Kostamo, Riitta Pasanen and Atte Mikkelson from VTT are acknowledged for their excellent technical assistance.

\section{References}

1 EFSA, Scientific Opinion on the substantiation of health claims related to beta-glucans and maintenance of normal blood cholesterol concentrations (ID 754, 755, 757, 801, $1465,2934)$ and maintenance or achievement of a normal body weight (ID 820, 823) pursuant to Article 13(1) of Regulation (EC) No 1924/2006, EFSA J., 2009, 7, 1254.

2 EFSA, Scientific Opinion on the substantiation of health claims related to beta-glucans from oats and barley and maintenance of normal blood LDL-cholesterol concentrations (ID 1236, 1299), increase in satiety leading to a reduction in energy intake (ID 851, 852), reduction of postprandial glycaemic responses (ID 821, 824), and "digestive function" (ID 850) pursuant to Article 13(1) of Regulation (EC) No 1924/2006, EFSA J., 2011, 9, 2207.

3 EFSA, Scientific Opinion on the substantiation of a health claim related to oat beta-glucan and lowering blood cholesterol and reduced risk of (coronary) heart disease pursuant to Article 14 of Regulation (EC) No 1924/2006, EFSA J., 2010, 8, 1885.

4 EFSA, Scientific Opinion on the substantiation of health claims related to oat and barley grain fibre and increase in faecal bulk (ID 819, 822) pursuant to Article 13(1) of Regulation (EC) No 1924/2006, EFSA J., 2011, 9, 2249.

5 M. M. L. Grundy, A. Fardet, S. M. Tosh, G. T. Rich and P. J. Wilde, Processing of oat: The impact on oat's cholesterol lowering effect, Food Funct., 2018, 9, 13281343.

6 H. Anttila, T. Sontag-Strohm and H. Salovaara, Viscosity of beta-glucan in oat products, Agric. Food Sci., 2004, 13, 8087.

7 Y. Mälkki and E. Virtanen, Gastrointestinal effects of oat bran and oat gum a review, LWT-Food Sci. Technol., 2001, 34, 337-347.

8 A. Mackie, N. Rigby, P. Harvey and B. Bajka, Increasing dietary oat fibre decreases the permeability of intestinal mucus, J. Funct. Foods, 2016, 26, 418-427.

9 K. Korompokis, L. Nilsson and C. Zielke, The effect of in vitro gastrointestinal conditions on the structure and conformation of oat $\beta$-glucan, Food Hydrocolloids, 2018, 77, 659-668.

10 P. Gunness and M. J. Gidley, Mechanisms underlying the cholesterol-lowering properties of soluble dietary fibre polysaccharides, Food Funct., 2010, 1, 149-155.

11 S. R. Bridges, J. W. Anderson, D. A. Deakins, D. W. Dillon and C. L. Wood, Oat bran increases serum acetate of hypercholesterolemic men, Am. J. Clin. Nutr., 1992, 56, 455-459.

12 K. M. Queenan, M. L. Stewart, K. N. Smith, W. Thomas, R. G. Fulcher and J. L. Slavin, Concentrated oat $\beta$-glucan, a fermentable fiber, lowers serum cholesterol in hypercholesterolemic adults in a randomized controlled trial, Nutr. J., 2007, 6, 1-8.

13 A. Lazaridou, C. G. Biliaderis and M. S. Izydorczyk, Molecular size effects on rheological properties of oat 
$\beta$-glucans in solution and gels, Food Hydrocolloids, 2003, 17, 693-712.

14 A. Whitehead, E. Beck, S. Tosh and T. Wolever, Cholesterollowering effects of dietary fiber: A meta-analysis, Am. J. Clin. Nutr., 2014, 100, 1413-1421.

15 T. M. S. Wolever, S. M. Tosh, A. L. Gibbs, J. Brand-Miller, A. M. Duncan, V. Hart, B. Lamarche, B. A. Thomson, R. Duss and P. J. Wood, Physicochemical properties of oat $\beta$-glucan influence its ability to reduce serum LDL cholesterol in humans: A randomized clinical trial, Am. J. Clin. Nutr., 2010, 92, 723-732.

16 M. Biörklund, A. van Rees, R. P. Mensink and G. Önning, Changes in serum lipids and postprandial glucose and insulin concentrations after consumption of beverages with $\beta$-glucans from oats or barley: A randomised dose-controlled trial, Eur. J. Clin. Nutr., 2005, 59, 1272-1281.

17 J. M. Keenan, M. Goulson, T. Shamliyan, N. Knutson, L. Kolberg and L. Curry, The effects of concentrated barley $\beta$-glucan on blood lipids in a population of hypercholesterolemic men and women, Br. J. Nutr., 2007, 97, 1162-1168.

18 E. Naumann, A. B. Van Rees, G. Önning, R. Öste, M. Wydra and R. P. Mensink, $\beta$-Glucan incorporated into a fruit drink effectively lowers serum LDL-cholesterol concentrations, Am. J. Clin. Nutr., 2006, 83, 601-605.

19 S. M. Tosh, Y. Brümmer, T. M. Wolever and P. J. Wood, Glycemic response to oat bran muffins treated to vary molecular weight of $\beta$-glucan, Cereal Chem., 2008, 85, 211-217.

20 M. G. Y. Kwong, T. M. S. Wolever, Y. Brummer and S. M. Tosh, Attenuation of glycemic responses by oat $\beta$-glucan solutions and viscoelastic gels is dependent on molecular weight distribution, Food Funct., 2013, 4, 401408.

21 A. Rieder, S. H. Knutsen, A. Sainz Fernandez and S. Ballance, At a high dose even partially degraded betaglucan with decreased solubility significantly reduced the glycaemic response to bread, Food Funct., 2019, 10, 15291539.

22 L. Flander, M. Salmenkallio-Marttila, T. Suortti and K. Autio, Optimization of ingredients and baking process for improved wholemeal oat bread quality, LWT-Food Sci. Technol., 2007, 40, 860-870.

23 P. Åman, L. Rimsten and R. Andersson, Molecular weight distribution of $\beta$-glucan in oat-based foods., Cereal Chem., 2004, 81, 356-360.

24 W. F. Broekaert, C. M. Courtin, K. Verbeke, T. van de Wiele, W. Verstraete and J. A. Delcour, Prebiotic and other healthrelated effects of cereal-derived arabinoxylans, arabinoxylan-oligosaccharides, and xylooligosaccharides, Crit. Rev. Food Sci. Nutr., 2011, 51, 178-194.

25 H. W. Lopez, M. A. Levrat, C. Guy, A. Messager, C. Demigné and C. Rémésy, Effects of soluble corn bran arabinoxylans on cecal digestion, lipid metabolism, and mineral balance (Ca, Mg) in rats, J. Nutr. Biochem., 1999, 10, 500509.

26 N. Rosa-Sibakov, K. Poutanen and V. Micard, Trends Food Sci. Technol., 2015, 41, 118-134.
27 E. Arte, K. Katina, U. Holopainen-Mantila and E. Nordlund, Effect of hydrolyzing enzymes on wheat bran cell wall integrity and protein solubility, Cereal Chem., 2016, 93, 162-171.

28 A. Suurnäkki, M. Tenkanen, M. Siika-Aho, M. L. NikuPaavola, L. Viikari and J. Buchert, Trichoderma reesei cellulases and their core domains in the hydrolysis and modification of chemical pulp, Cellulose, 2000, 7, 189-209.

29 M. Bailey and K. Nevalainen, Induction, isolation and testing of stable Trichoderma reesei mutants with improved production of solubilising cellulose, Enzyme Microb. Technol., 1981, 3, 153-157.

30 T. Suortti, Size-exclusion chromatographic determination of $\beta$-glucan with postcolumn reaction detection, J. Chromatogr. A, 1993, 632, 105-110.

31 S. Willför, A. Pranovich, T. Tamminen, J. Puls, C. Laine, A. Suurnäkki, B. Saake, K. Uotila, H. Simolin, J. Hemming and B. Holmbom, Carbohydrate analysis of plant materials with uronic acid-containing polysaccharides-A comparison between different hydrolysis and subsequent chromatographic analytical techniques, Ind. Crops Prod., 2009, 29, 571-580.

32 N. Mäkelä, O. Brinck and T. Sontag-Strohm, Viscosity of $\beta$-glucan from oat products at the intestinal phase of the gastrointestinal model, Food Hydrocolloids, 2020, 100, 105422.

33 M. Minekus, M. Alminger, P. Alvito, S. Ballance, T. Bohn, C. Bourlieu, F. Carrière, R. Boutrou, M. Corredig, D. Dupont, C. Dufour, L. Egger, M. Golding, S. Karakaya, B. Kirkhus, S. Le Feunteun, U. Lesmes, A. Macierzanka, A. Mackie, S. Marze, D. J. McClements, O. Ménard, I. Recio, C. N. Santos, R. P. Singh, G. E. Vegarud, M. S. J. Wickham, W. Weitschies and A. Brodkorb, A standardised static in vitro digestion method suitable for food - an international consensus, Food Funct., 2014, 5, 1113-1124.

34 G. Rodríguez-Gutiérrez, F. Rubio-Senent, A. Lama-Muñoz, A. García and J. Fernández-Bolaños, Properties of lignin, cellulose, and hemicelluloses isolated from olive cake and olive stones: Binding of water, oil, bile acids, and glucose, J. Agric. Food Chem., 2014, 62, 8973-8981.

35 E. Nordlund, A. M. Aura, I. Mattila, T. Kössö, X. Rouau and K. Poutanen, Formation of phenolic microbial metabolites and short-chain fatty acids from rye, wheat, and oat bran and their fractions in the metabolical in vitro colon model, J. Agric. Food Chem., 2012, 60, 8134-8145.

36 J. Sibakov, O. Myllymäki, T. Suortti, A. Kaukovirta-Norja, P. Lehtinen and K. Poutanen, Comparison of acid and enzymatic hydrolyses of oat bran $\beta$-glucan at low water content, Food Res. Int., 2013, 52, 99-108.

37 E. Aktas-Akyildiz, J. Sibakov, M. Nappa, E. Hytönen, H. Koksel and K. Poutanen, Extraction of soluble $\beta$-glucan from oat and barley fractions: Process efficiency and dispersion stability, J. Cereal Sci., 2018, 81, 60-68.

38 E. Nordlund, K. Katina, A. M. Aura and K. Poutanen, Changes in bran structure by bioprocessing with enzymes and yeast modifies the in vitro digestibility and ferment- 
ability of bran protein and dietary fibre complex, J. Cereal Sci., 2013, 58, 200-208.

39 J. P. Martinant, A. Billot, A. Bouguennec, G. Charmet, L. Saulnier and G. Branlard, Genetic and environmental variations in water-extractable arabinoxylans content and flour extract viscosity, J. Cereal Sci., 1999, 30, 45-48.

40 N. Mathlouthi, L. Saulnier, B. Quemener and M. Larbier, Xylanase, $\beta$-glucanase, and other side enzymatic activities have greater effects on the viscosity of several feedstuffs than xylanase and $\beta$-glucanase used alone or in combination, J. Agric. Food Chem., 2002, 50, 5121-5127.

41 J. K. Hyun and P. J. White, In vitro bile-acid binding and fermentation of high, medium, and low molecular weight $\beta$-glucan, J. Agric. Food Chem., 2010, 58, 628-634.

42 S. Sayar, J. L. Jannink and P. J. White, Textural and bile acid-binding properties of muffins impacted by oat $\beta$-glucan with different molecular weights, Cereal Chem., 2011, 88, 564-569.

43 S. Naumann, U. Schweiggert-Weisz, S. Bader-Mittermaier, D. Haller and P. Eisner, Differentiation of adsorptive and viscous effects of dietary fibres on bile acid release by means of in vitro digestion and dialysis, Int. J. Mol. Sci., 2018, 19, 2193.

44 R. K. Bowles, K. R. Morgan, R. H. Furneaux and G. D. Coles, 13C CP/MAS NMR study of the interaction of bile acids with barley $\beta$-D-glucan, Carbohydr. Polym., 1996, 29, 7-10.

45 C. Zacherl, P. Eisner and K. H. Engel, In vitro model to correlate viscosity and bile acid-binding capacity of digested water-soluble and insoluble dietary fibres, Food Chem., 2011, 126, 423-428.

46 E. Marasca, S. Boulos and L. Nyström, Bile acid-retention by native and modified oat and barley $\beta$-glucan, Carbohydr. Polym., 2020, 236, 116034.
47 L. Ellegård and H. Andersson, Oat bran rapidly increases bile acid excretion and bile acid synthesis: An ileostomy study, Eur. J. Clin. Nutr., 2007, 61, 938-945.

48 I. Y. Bae, S. Lee, S. M. Kim and H. G. Lee, Effect of partially hydrolyzed oat $\beta$-glucan on the weight gain and lipid profile of mice, Food Hydrocolloids, 2009, 23, 2016-2021.

49 P. Gunness, B. A. Williams, W. J. J. Gerrits, A. R. Bird, O. Kravchuk and M. J. Gidley, Circulating triglycerides and bile acids are reduced by a soluble wheat arabinoxylan via modulation of bile concentration and lipid digestion rates in a pig model, Mol. Nutr. Food Res., 2016, 60, 642-651.

50 A. Bagdi, S. Tömösközi and L. Nyström, Structural and functional characterization of oxidized feruloylated arabinoxylan from wheat, Food Hydrocolloids, 2017, 63, 219-225.

51 H. J. Kim and P. J. White, Optimizing the molecular weight of oat $\beta$-glucan for in vitro bile acid binding and fermentation, J. Agric. Food Chem., 2011, 59, 10322-10328.

52 M. S. Mikkelsen, M. G. Jensen and T. S. Nielsen, Barley beta-glucans varying in molecular mass and oligomer structure affect cecal fermentation and microbial composition but not blood lipid profiles in hypercholesterolemic rats, Food Funct., 2017, 8, 4723-4732.

53 T. Immerstrand, K. E. Andersson, C. Wange, A. Rascon, P. Hellstrand, M. Nyman, S. W. Cui, B. Bergenståhl, C. Trägårdh and R. Öste, Effects of oat bran, processed to different molecular weights of beta;-glucan, on plasma lipids and caecal formation of SCFA in mice, Br. J. Nutr., 2010, 104, 364-373.

54 B. Damen, J. Verspreet, A. Pollet, W. F. Broekaert, J. A. Delcour and C. M. Courtin, Prebiotic effects and intestinal fermentation of cereal arabinoxylans and arabinoxylan oligosaccharides in rats depend strongly on their structural properties and joint presence, Mol. Nutr. Food Res., 2011, 55, 1862-1874. 